\title{
Finite-Element Mode for Parametric Analysis of Wood Frame Shear Walls
}

\author{
Jie Bai*, Na Li, Pengcheng Duan \\ School of Civil Engineering, \\ Guizhou University, \\ Guiyang, 550000, China \\ 147954114@qq.com, 312091626@qq.com, 770559006@qq.com
}

\begin{abstract}
Light wood-frame house is still developing in China and systematic research on light wood-frame house has yet to be carried out. In this paper, the analysis model of wood-frame shear walls is set by using ABAQUS. In terms of finite element program's computing results, the effect of opening size and location on shear walls is analyzed. The results have shown that the larger the opening is, the more significantly the bearing capacity reduces; the location of the opening has an obvious influence on resistance of shear walls to lateral loading.
\end{abstract}

Keywords-wood-frame shear walls; finite-element model; stress; axial compression ratio; opening

\section{INTRODUCTION}

The light wooden structure is the use a uniformly dense wood component specifications to withstand all kinds of planes and space houses the role of the force system. Is widely used in some developed countries, this form of light wood frame structure in North America, Canada and Japan, more complete theoretical system, technology is relatively mature. With the recent light wood structure house more widely used in China, it is necessary to carry out theoretical and experimental studies for systematic light wood structures, in order to promote the development of China's light wooden architecture.

After the 1980s, due to the significant reduction in China's timber supply, the development of wooden architecture basically stagnant. In recent years, a growing concern with the Chinese construction industry, energy saving and environmental protection construction, wood frame house abroad to enter the Chinese market, and a lot of light wood construction lumber imports, China's wooden architecture began to recover, using a range of light wood frame construction also gradually expanded.

Based on the wood frame shear walls is composed of light wood frame houses system, the most important force component, its study on the performance is to improve the basic content of the theoretical system of light wood frame. In this paper, finite element software ABAQUS of light wood frame shear wall parametric analysis, dimension width respectively $1.2 \mathrm{~m}, 2.4 \mathrm{~m}$ combine different location, these several dimensions the order of wood frame shear walls model finite element analysis. Gain corresponding influence law and

This work was financially supported by Guizhou Province Science and Technology Foundation (QianKeHe J [2010] 2246). main parameters affecting wood frame shear walls force performance.

\section{FinITE ELEMENT METHODS FOR SHEAR WALL ANALYSIS MODEL}

In this chapter, a finite element analysis of shear walls is conducted. Two commercial finite element programs, ANSYS and ABAQUS, are demonstrated. The new analytic model is implemented into ABAQUS and validated against the measured experimental data for monotonic and parametric studies (Table I).

The solution of nonlinear finite element equations is accomplished using the Newton-Raphson iterative algorithm. Typically automatic incremental solution control is used, where convergence occurs when the magnitude of the out-of-balance force or moment is within $0.005 \%$ of the maximum magnitude of force or moment. Some analyses require direct control increment. Implicit direct-integration is used for dynamic analyses.

TABLE I. FINITE-ELEMENT REPRESENTATION OF STRUCTURAL COMPONENTS

\begin{tabular}{|c|c|c|}
\hline $\begin{array}{l}\text { Structural } \\
\text { Component }\end{array}$ & Finite-Element Representation & $\begin{array}{c}\text { ABAQUS } \\
\text { Element } \\
\text { Designation }\end{array}$ \\
\hline Framing & Beam element: 2-node & B21 \\
\hline Sheathing & $\begin{array}{c}\text { Solid element: 8-node plain stress, } \\
\text { reduced integration }\end{array}$ & CPS8R \\
\hline $\begin{array}{l}\text { Sheathing-to- } \\
\text { Framing } \\
\text { Connections }\end{array}$ & Spring element: 2-nodes,nonlinear & SPRING2 \\
\hline Chord Splices & Spring element: 2-nodes, linear & SPRING2 \\
\hline
\end{tabular}




\section{VALIDATE FINITE ELEMENT MODEL}

Experimental studies of wood-frame shear walls have been performed by many researchers in recent years. This paper establishes a new finite-element model based on making a parametric analysis on wood-frame shear walls. For the accuracy of the model, analog values and experimental data [2] contrast verification. After verification (Fig. 1), the model established in this paper has a high degree of accuracy. Therefore, you can use this model to analyze the parameters of wood structural shear walls.

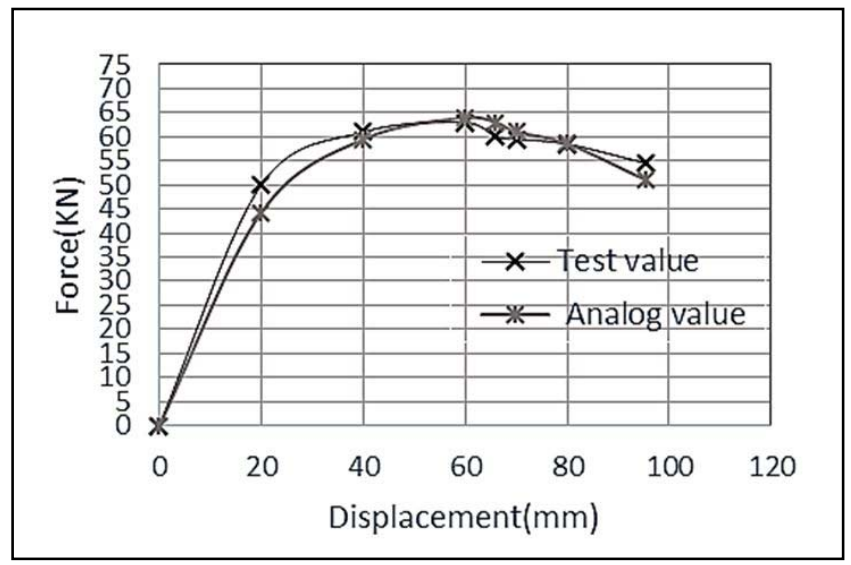

Fig. 1. Load-displacement curve.

\section{PARAMETRIC ANALYSIS}

This paper has established a wood-frame shear wall model with four different shear wall opening locations. Q1 is the opening width $(1.2 \mathrm{~m})$ in the middle position. Q2 is the opening width $(1.2 \mathrm{~m})$ in the offset position. Q3 is the opening width $(2.4 \mathrm{~m})$ in the middle position. Q4 is the opening width $(2.4 \mathrm{~m})$ in the offset position. Q5 is the whole piece of the wall. Q6 is that the axial force is applied to the entire piece of wall. Q7 is that the axial force is applied to opening width $(1.2 \mathrm{~m})$ in the middle position. Q8 is that axial force is applied to opening width $(2.4 \mathrm{~m})$ in the middle position. The following four shear wall models will carry out a parameters analysis, like Fig. 2.

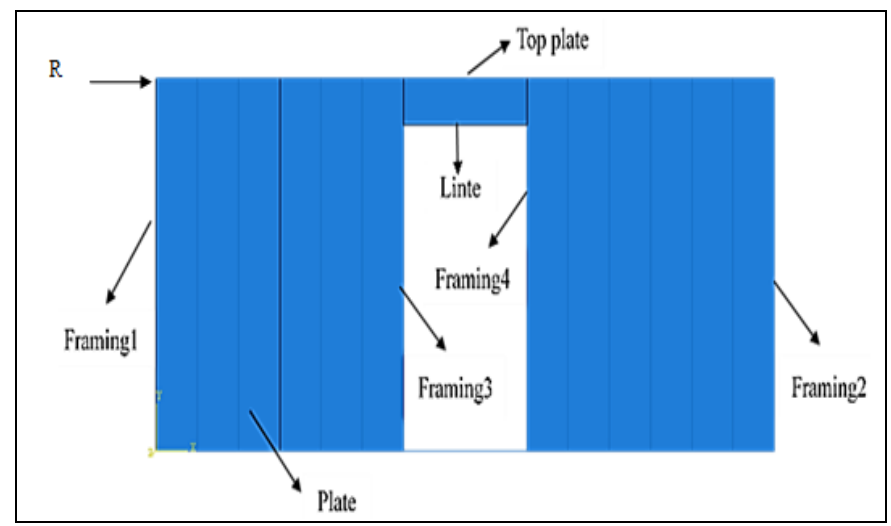

Fig. 2. Schematic model.

\section{A. Wood frame shear wall Lateral Force.}

The shear wall structure has a good carrying capacity, and has good integrity and space effect, then the frame structure has better lateral force-resisting capability. A shear wall is an important bearing member to the light wood-frame house, and lateral force-resisting capability of research is essential. Shear wall opening and changes in the opening location will affect its resistance to lateral forces and this is the article to study one of the elements. Fig. 3 can be seen very intuitively: The bigger the opening, the smaller the lateral resistance of wall. At the same time, the lateral resistance of the wall will be significantly reduced by non-centered opening.

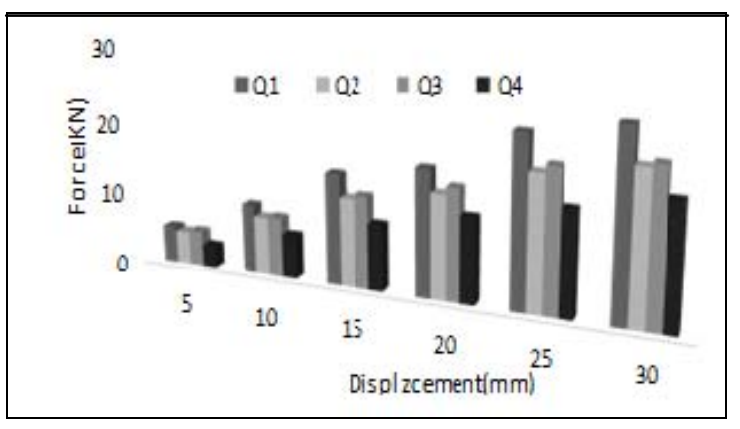

Fig. 3. Force and displacement relationship.

\section{B. Stress analysis of framing}

From Fig. 4, the centered opening has little influence on stress distribution of side columns. When the opening is offset, the side columns near the opening are under the tensile stress, the uptrend of wall is more obvious under the load effect. Stress on both sides of the opening will be increased by the large opening and bias.

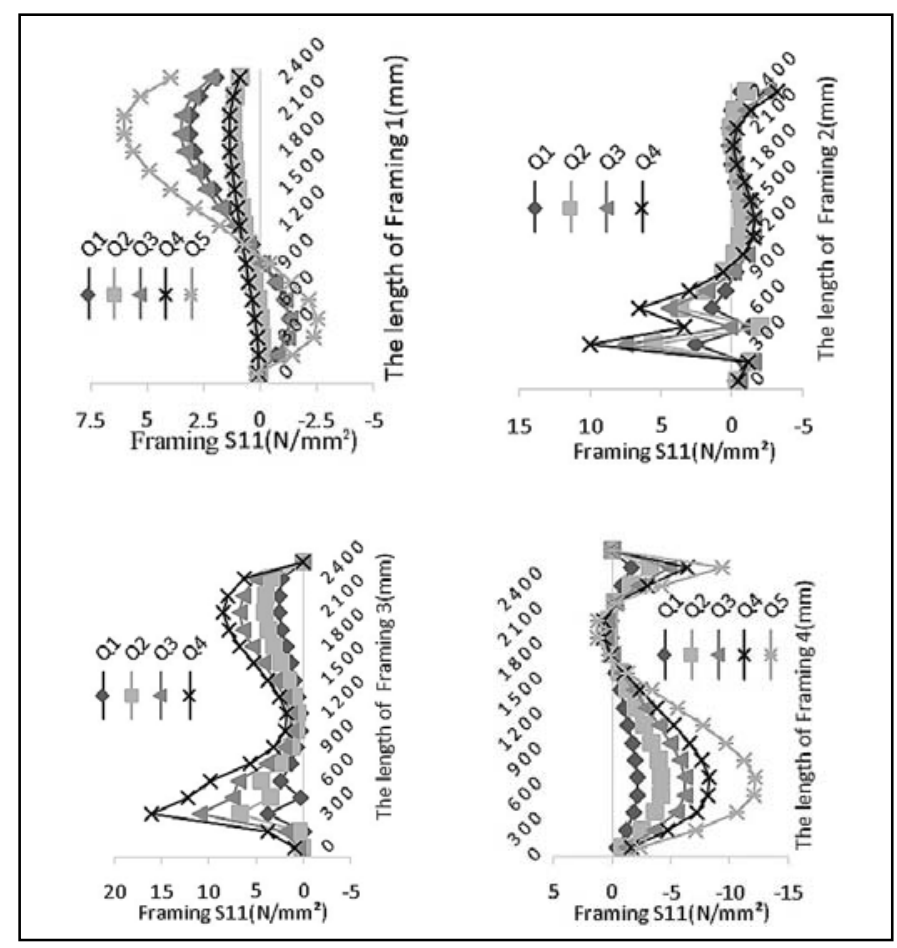

Fig. 4. Curves of framing force distribution. 


\section{Stress Analysis of top plate}

From Fig. 5, the larger the opening, the bigger the stress of top beams, and the top beam stress will be increased when the eccentricity becomes greater, and stress of the joint between top beam and the plate is larger.

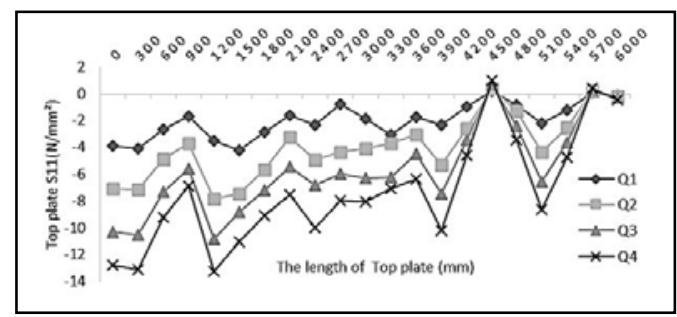

Fig. 5. Curves of top plate force distribution.

\section{Stress Analysis plate}

From Fig. 6, under the same displacement, the average stress value of plate Model Q5 is greater than those of Model Q1 and Q2, and the stress on plate is most homogeneous; the part above the opening is close to 0 , showing that the opening cannot transmit force effectively, resulting in a decline in overall mechanical properties of the wall.

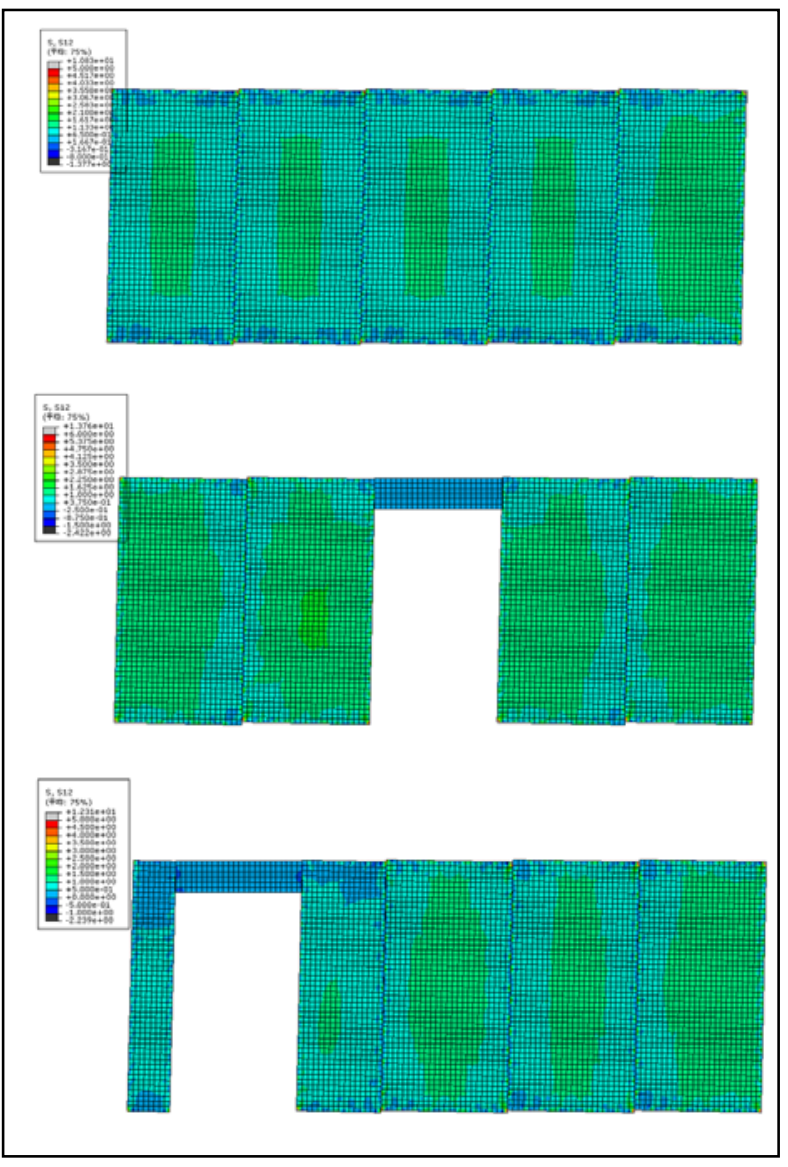

Fig. 6. Plate stress cloud

\section{E. Influence of under axial compression}

From Fig. 7, when the axial compression stress is applied, the member stress of Model Q8 has relatively more uniformly increased than Model Q5; the stress near the opening in Model Q6 increases more sharply than in Model Q1. The analysis results have shown that the bigger the opening, the larger the influential region of axial compression ratio. Contrast load displacement curve can be seen in Fig. 8; applying axial compression can effectively improve the bearing capacity of the wall, with an increase in displacement loading; the axial pressure helps to improve the ability to resist side obviously.

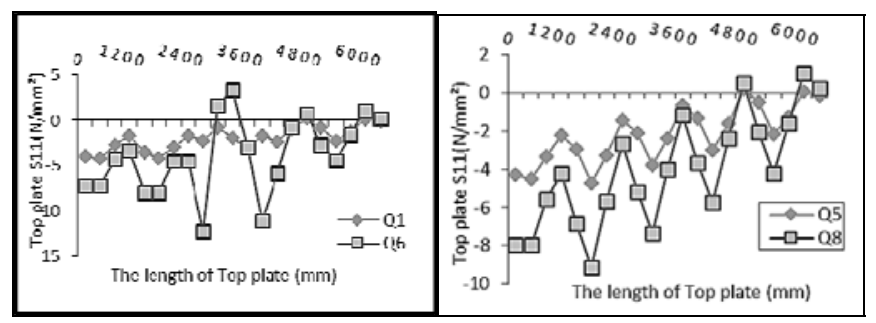

Fig. 7. Curves of top plate force distribution

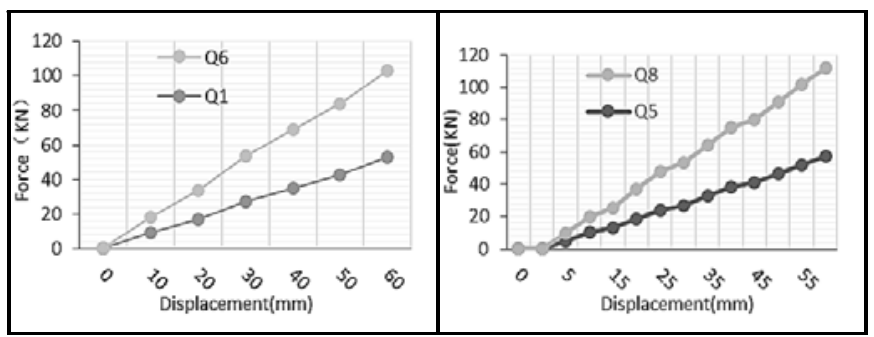

Fig. 8. Load - displacement curve

\section{CONCLUSIONS}

A preliminary analysis for the opening size and location on the shear wall shows that the opening size and location on the shear wall has obvious influences to resist lateral load of the shear wall. In short:

1) The lateral bearing capacity of the wall will reduce opening. The larger the opening, the more significantly the bearing capacity reduces;

2) The location of the opening has obvious influences on the wall stress. The bearing capacity will decrease obviously and the stress of columns near opening is adverse by the large opening bias;

3) A proper axial compression ratio will improve the carrying capacity of the wall effectively, but attention should be paid to reinforcing the top beam and the upper part of the opening. 


\section{REFERENCES}

[1] Wood Design Manual.2005: Canada Wood Council.

[2] Y.H. Qian. The finite element analysis of wood frame shear walls. D .Yangzhou University, 2012.

[3] J.P. Judd, Finite Element Analysis of Wood Shear Walls and Diaphragms Using ABAQUS. ABAQUS Users Conference, 2002.

[4] J. Xu, J. Daniel, and F. Dolan, "ASCE, Development of a Wood-Frame Shear Wall Model in ABAQUS.” J. Struct. Eng., pp. 978-984, 2009.

[5] A.S. Blasetti, R.M. Hoffman, and D.W. Dinehart, "Simplified hysteretic finite-element model for wood and viscoelastic polymer connections for the dynamic analysis of shear walls.” J. Struct. Eng., vol. 134, pp. 77-86, 2008.

[6] G. Doudak, I. Smith, G. McClure, M. Mohammad, and P. Lepper, "Tests and finite element models of wood light-frame shear walls with openings.” J. Struct. Eng. and Mat., vol. 8, no.4, pp. 165-174, 2006.

[7] M. He , H. Magnusson, F. Lam, and H.G.L. Prion.” Cyclic performance of perforated wood shear walls with oversize OSB panels.” J. Struct. Eng. vol. 125, no. 1, pp.10-18, 1999.

[8] B. Folz, and A. "Filiatrault Cyclic analysis of wood shear walls." J. Struct. Eng. vol 127, no. 4, pp. 433-441, 2001. 